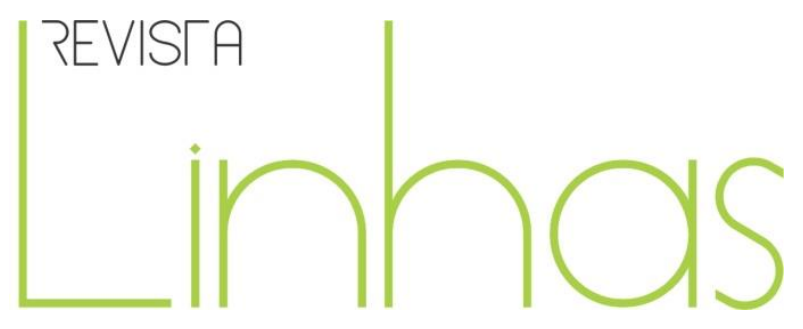

\title{
Processos pedagógicos manuais ou tecnológicos: desenvolvimento de habilidades fundamentais na formação inicial do Designer
}

\begin{abstract}
Resumo
O artigo apresenta o início da pesquisa sobre processos pedagógicos manuais ou tecnológicos, nos Cursos de Design em disciplinas práticas de desenvolvimento de produto. Propomos a discussão sobre o potencial dos dois processos e a análise com relação à valorização do processo tecnológico, com o uso da impressora 3D, em detrimento do processo manual. Trazemos as Diretrizes Curriculares Nacionais e algumas publicações sobre a impressora 3D, no campo da educação, assim como a experiência de uma das pesquisadoras na docência de cursos superiores de Design em que vivencia 0 distanciamento de práticas que desenvolvem competências manuais e o processo criativo de produtos com modelagem manual que valorizam a autoria do designer no desenvolvimento de suas habilidades. Esta primeira fase do estudo é bibliográfica interdisciplinar e dialoga com as pesquisadoras, docentes do Ensino Superior, que analisam o desenvolvimento de habilidades nos dois processos de aprendizagem do futuro designer.
\end{abstract}

\footnotetext{
Claudia Coelho Hardagh

Universidade Presbiteriana

Mackenzie - São Paulo/Brasil

hardagh@gmail.com

Eloisa Camargo Penna

Universidade Presbiteriana

Mackenzie - São Paulo/Brasil elopenna1@gmail.com
}

Palavras-chave: Processos Pedagógicos. Modelagem Manual. Impressora 3D. Habilidades. Designer.

\footnotetext{
Para citar este artigo:

HARDAGH, Claudia Coelho; PENNA, Eloisa Camargo. Processos pedagógicos manuais ou tecnológicos: desenvolvimento de habilidades fundamentais na formação inicial do Designer. Revista Linhas.

Florianópolis, v. 18, n. 36, p. 285-304, jan./abr. 2017.
} 


\title{
Manual or technological pedagogical processes: key skills development in initial designer training
}

\begin{abstract}
The article presents the first steps of a research on manual or technological pedagogical processes, in product development hands-on classes of the Design Undergraduate School. We propose a discussion on the potential of the two processes and the analysis regarding the appreciation of the technological process with the use of 3D printers, to the detriment of the manual process. We further display the National Curriculum Guidelines and some publications about 3Dprinter use in the field of education, as well as report the experience of one researcher of the teaching activity in degree courses of Design, who experiences the distancing from practices that develop manual skills in the creative process of products with manual modeling, something that would value the authorship of the designer as he develops his skills. This first phase of the study is an interdisciplinary bibliographical review, and enters in dialogue with the researchers, higher education teachers that analyze the development of skills in both learning processes of the future designer.
\end{abstract}

Keywords: Pedagogical Processes. Manual Modeling. 3D Printer. Skills. Designer. 


\section{Introdução}

O uso de tecnologia computacional e digital na educação tem sido foco de pesquisas em todo mundo; muitos autores escrevem sobre a necessidade de inserir ferramentas e novas linguagens numa perspectiva pedagógica que explore o potencial do mundo digital, o ciberespaço e as ferramentas desenvolvidas que vão de tablets e celulares à impressora 3D. Esta última vem ocupando espaço nas mídias, pois rapidamente a popularização das impressoras $3 \mathrm{D}^{1}$ e sua utilização na educação, nos processos de aprendizagem, passou a ser alternativa em vários segmentos da área.

O foco deste artigo fica por conta da discussão sobre o uso desta tecnologia que, além da indústria, vai desde o campo da medicina até o campo aeroespacial, sendo citada também nas pesquisas da área de educação e, aos poucos, fazendo parte da infraestrutura de algumas escolas no Brasil e no exterior.

Segundo o blog Impressão 3D², em 2014, muitos jovens estudantes estavam buscando entender e aplicar o potencial desta tecnologia por conta própria, ao mesmo tempo em que as escolas nos EUA e Reino Unido se organizavam para incorporar as impressoras 3D nas salas de aula como recurso pedagógico auxiliador para a formação destes jovens. Assim como outras ferramentas utilizadas na indústria, segurança ou serviços, a impressora 3D, começa a ser disseminada primeiro no mercado e demora algum tempo para ser apropriada como artefato pedagógico pelos professores.

Uma jovem, quando tinha 11 anos, teve seu primeiro contato com a impressora 3D, quando participou do Festival de Ciência e mais tarde no Lab Fab, ${ }^{3}$ ambos em Manchester, marcando sua vida e despertando o interesse em buscar essa tecnologia. Aos 13 anos, em 2013, ganhou o primeiro "Menina Europeia da Comissão Europeia Digital”4. Isso mostra o descompasso entre os anseios dos jovens, autonomia e criatividade associados às

\footnotetext{
${ }^{1}$ Segundo o canal do ensino, por Ismael Oliveira "impressão 3D é uma tecnologia que permite moldar objetos a partir de polímeros (plástico) por uma máquina (impressora)”.

2 Disponível em: <http://impressao3dprinter.com.br/blog/2014/04/impressao-3d-na-sala-de-aula-tambem/>. Acessado em: 22 de maio de 2015.

${ }^{3}$ Laboratório de Fabricação Digital.

4 Disponível em: <http://impressao3dprinter.com.br/blog/2014/04/impressao-3d-na-sala-de-aula-tambem/>. Acessado em: 22 de maio de 2015.
} 
tecnologias digitais e o distanciamento da educação em atrelar o currículo, formação dos professores e prática pedagógica às mudanças tecnológicas.

Um estudo 5 publicado em 2014, pela New Media Consortium (NMC) - Horizon Report ${ }^{6}$, apresentou as tendências de mudança na educação superior em um período de três a cinco anos. Entre elas, a impressão 3D é apontada como nova tecnologia que pode ter um impacto na educação superior, se tornando uma ferramenta importante para o professor otimizar suas aulas, desenvolvendo material de apoio ou ainda, como citado no Instituto Claro, "podem transformar o ambiente de ensino ao inserir professores e alunos em um contexto de criação conjunta e de troca real de conhecimentos" 7.

Outra tendência divulgada pelo NMC é a já conhecida "Flipped Classroom / sala de aula invertida" como forma de aprendizado que vem sendo implantada aos poucos, e está sendo incorporada nas escolas, segundo Hardagh (2012, p.56), deslocaria "os alunos da posição passiva de receptores de conteúdo, para a posição de construtores do conhecimento".

Segundo Adriana Gandin (2014), publicado no Diário de Inovações em 2014, a meta para a grande mudança na educação básica trata de "romper com uma lógica de que o professor ‘sabe tudo' e ‘que fala o tempo todo' e, no lugar, construir outro modelo onde há busca conjunta entre professores e alunos, construção coletiva e compartilhamento."

Os cursos de Design têm as suas especificidades em relação às disciplinas de projeto. Isso fica claro desde as Diretrizes Curriculares Nacionais - DCNs dos cursos que estabelecem em seu artigo $4^{\circ}$ as habilidades e competências desejáveis para a formação profissional dos egressos. Das oito recomendações, duas referem-se diretamente ao tema deste artigo:

II - capacidade para o domínio de linguagem própria expressando conceitos e soluções, em seus projetos, de acordo com as diversas técnicas de expressão e reprodução visual;

\footnotetext{
${ }^{5} \mathrm{O}$ Estudo foi feito com mais de 50 pesquisadores de 13 países, incluindo o Brasil.

6 Disponível em: <http://www.nmc.org/publication/nmc-horizon-report-2014-higher-education-edition/>. Acessado em: maio de 2015.

${ }^{7}$ Disponível em: <https://www.institutoclaro.org.br/blog/as-impressoras-3d-podem-mudar-a-sala-de-aula-/>. Acessado em: maio de 2015.
} 
V - domínio das diferentes etapas do desenvolvimento de um projeto, a saber: definição de objetivos, técnicas de coleta e de tratamento de dados, geração e avaliação de alternativas, configuração de solução e comunicação de resultados; ${ }^{8}$ (Resolução $n^{\circ}$ 5, de 08 de Março de 2004)

As competências em disciplinas de projeto de Produto são claras quanto à necessidade da confecção de modelos volumétricos em diferentes materiais respeitando as etapas projetuais. Os modelos podem ser confeccionados com diversas técnicas de modelagem física. No entanto, há duas linhas que se opõem quanto à linguagem e ao processo de execução: a manual ou tradicional e, pelo outro lado, aquelas que fazem uso das tecnologias da impressão 3D. A dicotomia dos dois modelos fica explicitada com as mudanças curriculares e nos debates sobre a importância das aulas de produção manual em detrimento do uso da impressora e dos softwares. A bipolarização sobre qual modelo é o mais adequado não colabora para o entendimento de qual técnica é mais indicada para o desenvolvimento das habilidades necessárias ao Designer, e o mais imprescindível: a exequibilidade de escolher entre uma das duas alternativas pedagógicas.

Entendemos técnica como a capacidade cognitiva que o homem adquiriu em transformar materiais e objetos criando novos. A proposta colocada neste artigo e pesquisada propõe a hibridização das linguagens e a convergência de processos manual e tecnológico para o desenvolvimento de habilidades para a formação do Designer contemporâneo. A fundamental questão abordada em nosso estudo é como a técnica manual e as impressoras 3D podem convergir para o desenvolvimento de habilidades fundamentais no ensino do futuro Designer?

Para preparar este estudo foram feitos levantamentos de artigos, revistas e experiências sobre o tema e nos deparamos com a primeira dificuldade, que seria encontrar pesquisas realizadas na área de educação sobre aprendizagem ou formação do professor voltado para esta tecnologia. O material coletado ainda está nas redes sociais ou em relatos de professores e alunos que se aventuram a aplicar a técnica em aula, mas sem aprofundamento em fazer análises com o viés voltado para as questões

\footnotetext{
${ }^{8}$ Disponível em: <http://portal.mec.gov.br/cne/arquivos/pdf/rces05_04.pdf>. Acessado em julho de 2015.
} 
pedagógicas. Desta forma, este primeiro estudo ainda é um levantamento bibliográfico e experimental sobre o tema, que resultará em uma pesquisa de campo mais profunda.

A estrutura do artigo apresenta as duas abordagens: modelagem física - manual e modelagem mediada pela tecnologia computacional - impressora 3D; discutiremos as características, pontos positivos e negativos de cada uma dentro do ensino de Design na visão da mestranda do Programa de Educação, Arte e História da Cultura, professora e pesquisadora da disciplina Técnicas de Modelagem Física que, em parceria com a professora e pesquisadora da linha de formação de professores para uso de Tecnologias digitais, analisam este processo de aprendizagem dos estudantes de cursos de Design.

São múltiplas as técnicas de impressão 3D que não cabe aqui serem elencadas, razão pela qual faremos referência a elas de um modo genérico - modelagem tecnológica.

\section{Modelagem Manual}

Resultante de experiências praticadas há milênios, a modelagem manual tem como principal ferramenta a mão do homem, somada a sua habilidade de manusear os diferentes tipos de materiais e técnicas.

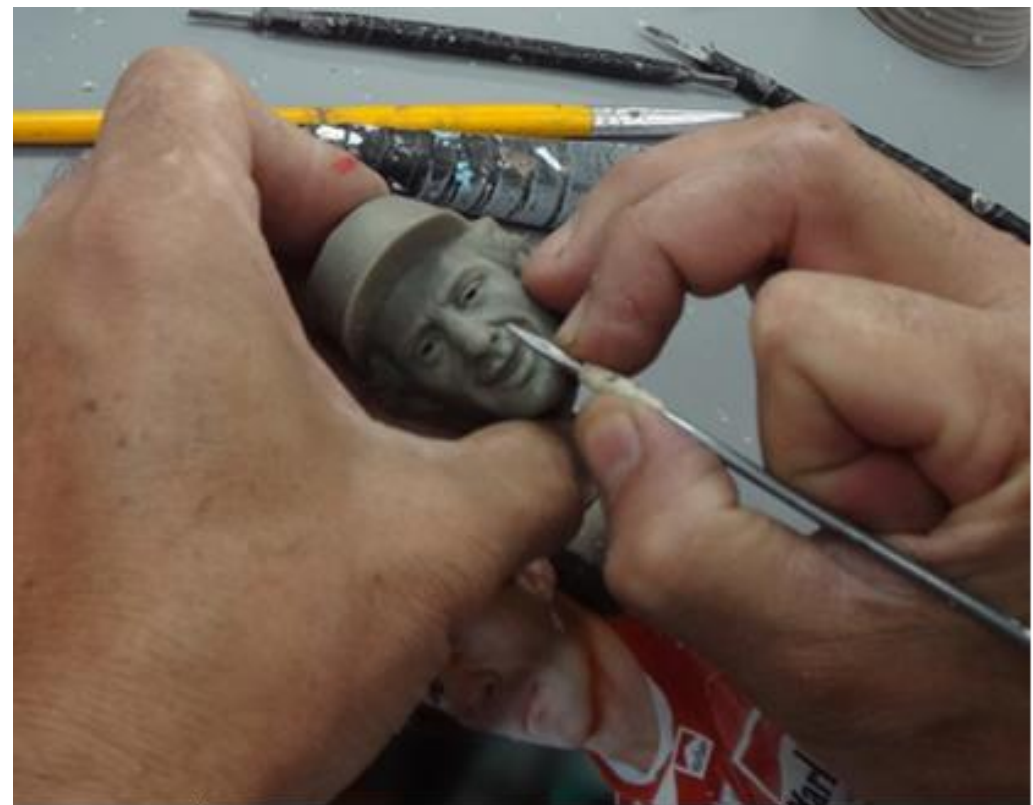

Fonte - Foto da pesquisadora
Figura 1 - Modelagem manual, correções feitas por Wilson Iguti no modelo de cera. 
Quando a sociedade se depara com novas tecnologias é comum fazermos apologia às suas qualidades e a previsão de morte das técnicas do passado. Isso ocorreu com o a fotografia analógica, cinema e televisão, e hoje vemos debates sobre a morte do livro impresso. A proposta aqui é a hibridização, convergência de linguagens que não são antagônicas, mas complementares, cada uma com seus valores e potencial para a formação de profissionais que saberão decidir pela opção mais adequada para cada situação enfrentada pelos futuros designers. O início de uma nova tecnologia não derruba a antiga. É um bom momento para fazermos uma análise crítica apresentando os vários lados desta disseminação acelerada da inovação, o que nos faz prosperar e o que fica esquecido ou até é destruído por ela. Segundo Postman,

(...) podemos aprender com isso que é um erro supor que qualquer inovação tecnológica tem efeito unilateral apenas. Toda tecnologia tanto é um fardo como uma benção; não uma coisa ou outra, mas sim isto e aquilo. [...] Minha defesa é a de que às vezes é preciso uma voz discordante para moderar a gritaria feita pelas multidões entusiásticas. (POSTMAN, 1994, p. 14-15)

Segundo depoimento de lan Hunter \& Matthew Gratzner (Visual Effects Supervisors - Hunter(Gratzner industries) apresentado no Canal History, de televisão paga, no documentário Maravilhas Modernas, com o título "Modelos" feito em 2000, "O computador, por um lado, expandiu o que fazemos. [...] Mas alguns acham que o computador resolve tudo. Os efeitos de maior sucesso são uma combinação de tudo" (grifo nosso).

A entrada da tecnologia digital e computacional na educação é um fato irreversível; temos que aprender a usar estas ferramentas didaticamente para propiciar uma ampla formação do aluno. Dentro desta linha de pensamento, defendemos a necessidade de reconhecer as qualidades da modelagem tecnológica para o designer de produto como um "dispositivo", no entanto, sem perder de vista as origens. Vale ressaltar que, segundo Borgman, “os dispositivos são essencialmente um meio (algopara), sendo necessário distinguir ainda entre a maquinaria do dispositivo e a sua função". (apud CUPANI, 2004, p.500). Fortalecer e valorizar a técnica da modelagem manual no ensino de Design soma conhecimentos, habilidades e competências no 
aprendizado. Trocar as ferramentas manuais pela tecnologia computacional faz parecer que ela é ultrapassada e não tem mais utilidade para o aluno e profissional do século XXI. Esta tendência cultural nos acompanha e o homem ao se deparar com novas invenções acredita que as antigas cairão em desuso. Como defende Jacquinot-Delaunay (2009)

\begin{abstract}
Quando uma nova mídia ou uma tecnologia aparece, ela é subitamente investida de uma potencialidade educativa... a realidade das práticas vem rapidamente desmentir; que uma nova mídia ou uma nova tecnologia nunca fazem desaparecer as antigas, mas modificam os seus usos: a real apropriação de uma mídia ou tecnologia em nível pedagógico, qualquer que seja o nível de escolaridade considerado, levam a termo a evolução do conjunto dos dispositivos educacionais no qual se inscreve aquela nova prática. (JACQUINOT-DELAUNAY, 2009, p. 166-167 Apud, SANTAELLA, 2010, p. 205)
\end{abstract}

À medida que novas tecnologias são apropriadas culturalmente pelos homens, o processo de metamorfose cognitivo ocorre para que o potencial humano, inteligência e conhecimento sejam colocados em uso para potencializar a tecnologia em consonância com o propósito para o qual foi destinada. Computador, Internet, máquina fotográfica, filmadora, celular e impressora 3D não foram desenvolvidos para fins educacionais, no entanto, novas práticas pedagógicas estão sendo incorporadas à educação por intermédio de seus usos.

Entretanto, cabe ao educador discernir o momento para inserir as tecnologias computacionais, ter clareza das vantagens e desvantagens em abandonar técnicas antigas, em incorporá-las às tecnologias novas ou torná-las pervasivas a todas as estratégias pedagógicas e protagonizar a tecnologia em detrimento de outras ferramentas de mediação.

Ao longo de nossa história, as artes, em geral, principalmente as habilidades manuais, ocuparam um papel importante na educação, principalmente nos colégios para meninas que tinham que bordar, costurar e produzir artefatos. Atualmente, a neurociência cognitiva, que tem contribuído para a pedagogia entender as mudanças cognitivas dos alunos, tem mostrado que o professor precisa fazer uso de várias estratégias e linguagens que estimulem o visual, o auditivo e o manual para o fortalecimento das sinapses e das redes neurais se estabelecer com mais facilidade. 
Diante de tantas novidades tecnológicas e de dispositivos que realizam múltiplas tarefas, as atividades manuais, gradativamente, estão ficando em segundo plano, ou até esquecidas ao longo do percurso escolar. Na infância, o "fazer" com as mãos possibilita desenvolver importantes habilidades para o desenvolvimento da psicomotricidade, sensibilidade artística e criatividade.

Fazendo um levantamento rápido sobre arte e tarefas manuais na vida escolar, isso tem relevância somente na educação infantil, pois se associa ao lúdico, à brincadeira e dissocia-se do currículo escolar em outras fases da educação, principalmente nas disciplinas duras.

O desenvolvimento da capacidade criativa e de atividades voltadas à produção artesanal e manual não são consideradas importantes em outros componentes curriculares e a Educação Artística deve dar conta da arte musical e visual deixando de ser transversal e interdisciplinar.

No Ensino Superior, os cursos de Design, mais específicos e direcionados ao processo criativo dos alunos, os componentes curriculares que têm em seus objetivos valorizar a criação e o desenvolvimento de produtos manuais - deveriam ser considerados fundamentais nos primeiros semestres em que o aluno passa a ter a percepção do que é e como é o processo criativo. Defendemos neste estudo que a modelagem leva ao aprimoramento da coordenação motora, senso estético e percepção visual para melhor compreender e faz com que o designer proponha com mais desenvoltura soluções de uso, função, ergonomia, propriedade dos materiais e até de processos de fabricação de um produto que pode, muitas vezes, ser refinado fazendo uso da técnica de modelagem manual. A modelagem ajuda na construção do pensamento dando forma ao que foi imaginado.

Gomes coloca que

A utilização de modelos físicos [...], é um extraordinário recurso com que pode contar o Designer. [...] Em resumo, trata-se de uma indispensável ferramenta que o Designer, sempre que possível, deve utilizar para garantir a adequada viabilização do projeto e materialização do produto final.

[...] chamamos a atenção para o fato de que é muito importante que o designer, em sua formação profissional adquira esses conhecimentos e 
habilidades para otimizar a sua performance projetual como um todo [...]. (GOMES FILHO, 2006, p. 217, grifo nosso)

Durante a jornada escolar, são muitos os materiais e técnicas com que o aluno tem contato em atividades artísticas na sala de aula ou através da bagagem de conhecimentos adquiridos ao longo da vida. Percebemos que também na educação básica há o mesmo dilema com relação às atividades manuais e artísticas. As aulas e atividades que exigem criatividade e manuseio de materiais são pouco incentivadas após a educação infantil e as atividades que usam o corpo e as mãos têm seu tempo reduzido no próprio currículo, pois se resumem às aulas de educação artística e educação física. Isso prejudica o desenvolvimento da visão espacial, da sensibilidade e de habilidades manuais.

Quando os jovens escolhem cursos de Artes, Arquitetura ou Design, já têm uma relação especial com o processo criativo pelo desenho e por atividades que exigem criatividade. Ao ingressarem nos cursos superiores, a alfabetização manual e artística advinda da escola básica tem uma aplicação totalmente dirigida à intencionalidade do projeto. Nas disciplinas de projeto, espera-se que o estudante consiga até o final do curso imaginar, desenhar e modelar uma solução projetual com coerência desde o início ao final, isto é, sem alterações que desvirtuem os principais conceitos norteadores. Podemos sintetizar que a técnica da modelagem manual possibilita a realização de ajustes finos sem perder a essência do projeto e, provavelmente, não haverá necessidade de fazer alterações drásticas da forma por não conseguir expressar-se com outros meios de representação. A modelagem manual valoriza o processo projetual e não um resultado certo e errado. Vigotski (1991) defende que o indivíduo, por ser social, constrói sua individualidade a partir das interações que se estabelecem entre os indivíduos, mediadas pela cultura, o fazer, motiva a relação com a teoria e esta é construída pelo aprendiz na avaliação do erro, no tentar e errar, reavaliar seu processo.

Inicia-se o desenvolvimento do projeto de um produto, pesquisando o tema, buscando soluções para questões funcionais, estéticas e de uso. Muitas ideias se tornam sketches. Os desenhos são feitos com base nas melhores soluções - esboços dimensionais. No pensamento podemos "tudo", não existe limite de forma, cor, material e processo; idealizamos o artefato perfeito. Ao transferir as ideias para o papel, ou 
computador, surgem as limitações das representações bidimensionais quanto à visualização da forma e a dificuldade em expressar o que está configurado como pensamento abstrato. Em termos de design, diz-se que o profissional dessa área trata de traduzir uma imagem mental em uma imagem visual. O modelo físico vai além, o traduz em um objeto palpável.

São várias as etapas nas quais se faz necessária a utilização dos modelos de verificação formal, para se realimentar o projeto na tradução da expressão bidimensional para o tridimensional.

Muitos estudantes têm capacidade de se expressar através de desenhos, com maior ou menor grau de elaboração - do esboço, esquema, passando pelo técnico e chegando ao ilustrativo. Outros procuram mostrar as idéias mediante modelos físicos. $O$ fato é que ambas as formas de expressão fazem parte dos diversos momentos do pensamento projetual.

Quando modelamos, as mãos guiadas pelo cérebro dão volume ao desenho bidimensional, busca na memória o conhecimento adquirido para fazer os ajustes necessários e a visão vai conferindo milimetricamente a forma que vai surgindo.

Quando se constrói o modelo junto com o desenvolvimento do projeto, ele vai resgatando e alimentando as informações sensórias motoras, que os desenhos não são capazes de demonstrar. Após a confecção do modelo de verificação formal é normal refinar os desenhos da proposta inicial.

Sass e Oxman (2006) colocam que o processo de construção de modelos pode conduzir para novas formas, além das alternativas originais. Para Coughlan, Suri e Canales (2007), fazer um protótipo envolve passar de uma ideia abstrata para uma ideia concreta. Essa visão aborda a oportunidade de materializar e validar as propostas feitas por meio de desenhos manuais. (apud MARTINS, 2014, p. 40)

As habilidades manuais relacionam-se com o processo criativo por serem considerada uma das linguagens de expressão do pensamento. Pensar, desenhar e modelar. No desenho, não existem limites "reais", mas, quando se passa para o modelo físico, começam a surgir as reais dificuldades de adequação da forma. Uma característica 
essencial do Designer é a experimentação que só é possível durante o manuseio de modelos físicos. Ao modelar manualmente, os erros de projeto são corrigidos em tempo real, pois a verificação vai acontecendo simultaneamente ao ato - modelar é sentir e perceber a forma diminuindo as chances de precisar refazer o modelo no caso do resultado não atender as expectativas. Além disso, enquanto se modela, surgem novas ideias, adaptações da forma ou simplesmente argumentos necessários para realimentar o projeto.

É importante salientar que a habilidade da modelagem deve ser exercitada e estimulada desde as disciplinas introdutórias [...], a fim de recuperar e instrumentalizar mais rapidamente o estudante, caso contrário, se incorre no risco de se exacerbar o afastamento entre este e o processo de execução de seus próprios trabalhos. (SILVA, 2007, p. 10)

Existem diferentes tipos de materiais para a confecção dos modelos; no início do projeto, devem-se utilizar os materiais de baixa complexidade, pois são fáceis de serem manipulados e com um custo acessível ao estudante, permitindo o estudo dimensional e formal rápido e eficiente. Nas etapas seguintes, a escolha dos materiais se dá de acordo com as necessidades do projeto; sempre verificando o melhor custo, tempo de execução e as suas adequações.

Com a utilização do modelo volumétrico, fica evidente que, com o auxílio desta técnica tridimensional, o desenvolvimento do conceito é otimizado [...]. Neste caso, o aluno através do processo de aprendizagem construtivista, desenvolve mecanismos de apreensão de uma realidade e aplica este conhecimento de forma prática e eficiente, na busca da solução do problema de Design proposto. (OLIVEIRA, 2010, p. 56)

Além da importância da técnica manual no ensino e no Design, apresentamos também o valor desta técnica milenar para um escultor. Para ele, a matéria (argila, clay) é a forma expressiva mais utilizada que permite traduzir sua personalidade, usando a mais antiga das ferramentas - a mão. Quando na modelagem for possível imprimir uma marca pessoal do escultor, ela se torna o diferencial de um bom trabalho.

Focillon coloca toda a força de expressão nas mãos do artista que vai executar a modelagem, que é totalmente diferente do trabalho do homem “comum”. 
O que distingue o sonho da realidade é o facto de o homem que sonha não poder criar uma arte: as suas mãos dormem. A arte faz-se com as mãos. Elas são o instrumento da criação, mas, antes do mais, o órgão do conhecimento. [...] O artista prolonga o privilégio da curiosidade da infância bem para lá dos limites dessa idade. Ele toca, apalpa, calcula o peso, mede o espaço, modela a fluidez do ar para aí prefigurar a forma, acaricia a superfície de todas as coisas, e é com a linguagem do tacto que compõe a linguagem da vista [...]. (FOCILLON, 2001, p. 114-115)

O processo de aprendizagem, segundo Vigotski (1991), se dá com o outro e na mediação por meio de instrumentos que assumem sua importância como linguagem, signos, ou seja, as ferramentas culturalmente construídas e contextualizadas se interpõem entre o sujeito e o objeto de conhecimento que potencializam o processo de aprendizagem e desenvolvimento de habilidades. Neste aspecto, a Mediação Simbólica em Vigotski diz respeito à relação do sujeito com o mundo considerando como uma relação mediada e não direta. As ferramentas digitais - modelo tecnológico - e as técnicas manuais, modelo manual - são fundamentais para a formação do Designer contemporâneo porque dentro do pensamento sócio-histórico de Vigotski, as questões sociais e culturais e o desenvolvimento do sujeito estão em aberto e é a sua relação com a aprendizagem que vai definir como o sujeito irá se desenvolver. Isso mostra a importância do professor na escolha das ferramentas de mediação e na intenção clara de que tipo de profissional ele deseja formar. Podemos colocar que o fortalecimento das sinapses e novas funções mentais formam-se dependendo das experiências sociais às quais os aprendizes são expostos.

Veremos como a tecnologia digital/computacional transformou a relação dos aprendizes com o processo criativo, ou seja, a aprendizagem nos cursos de Design.

\section{Impressão 3D}

$\mathrm{Na}$ era do computador, a trajetória meteórica da tecnologia genericamente denominada de impressão 3D vem trazendo constantes e complexas mudanças que se refletem no ensino do Design. Os estudantes dos cursos são indivíduos profundamente influenciados por encantos divulgados pelos adeptos desse modo de materializar formas idealizadas. Além desse encanto com a materialização da forma, a tecnologia que associa 
computador com internet nos permite ultrapassar o tempo e o espaço, gerando novos modos de contato. O que se projeta em uma sala de aula pode se materializar na impressora 3D a muitos quilômetros de distância dali, por exemplo.

Todo este universo que gira na velocidade da internet, pode ser conferido, por exemplo, nos museus e nos diversos objetos premiados, com qualidade e complexidade muitas vezes impossíveis de serem executados no passado. Os objetos produzidos através da impressão 3D nos libertam das limitações das ferramentas manuais, mas nos aprisionam na expressão da forma; carisma e pessoalidade são substituídos pela precisão técnica. A impressão 3D tem uma finalidade de produção, de mercado de demanda, mas para a aprendizagem devemos trazer processos e metodologias diferenciados que agreguem ao processo técnico e manual e, com isso, o aluno perceba as diferenças entre os dois e avalie o potencial de cada um.

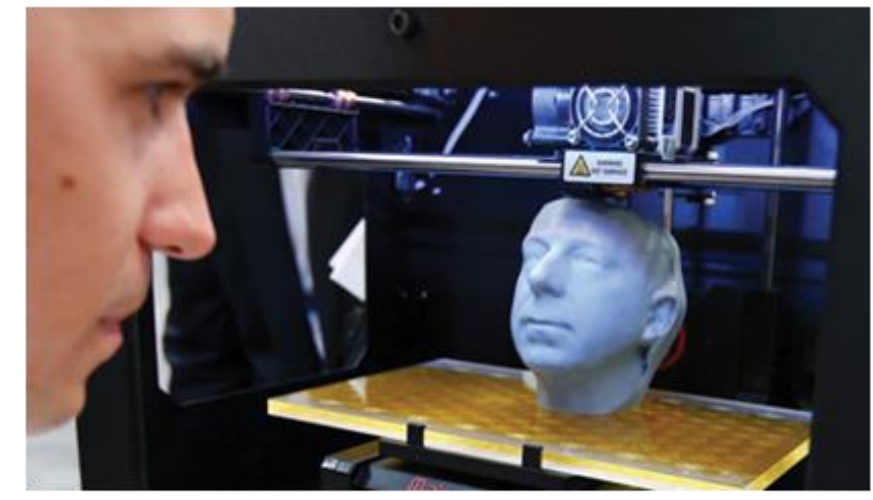

Fonte - http://waz.com.br/blog/2013/06/12/tudo-o-que-voce-precisa-saber-sobre-impressoras-3d/
Figura 2 -

Impressão 3D produzida em polímero

A modelagem tecnológica ainda possui um custo inicial elevado no Brasil, mas este investimento é fundamental nas instituições de ensino. Este dispositivo aparece na mídia constantemente devido a sua contribuição nas diversas áreas do conhecimento, sendo possível imprimir qualquer forma concebida em algum programa de desenho específico. Se a forma física já existir, ainda há o recurso do scanner e a reprodução de qualquer material que a modelagem tecnológica oferecer.

Em escolas ou para o público em geral, os materiais usados nas impressoras 3D mais comuns são o Plástico ABS, que tem a vantagem de permitir uma verificação formal básica do produto impresso e o gesso PLA que imprime o produto colorido oferecendo 
excelente qualidade para verificação estética, no entanto não é útil para ser submetido a testes por oferecer baixa resistência física.

No Brasil ambos os dispositivos possuem o melhor custo benefício até o momento. Para a produção industrial, existem mais opções de materiais e tipos de impressoras sendo utilizadas. As prestadoras de serviços cobram por hora/máquina e também é caro para os padrões dos alunos brasileiros; em torno de $\mathrm{R} \$$ 80,00 hora/máquina, sendo que uma peça do tamanho de um relógio pode custar $\mathrm{R} \$ 360,00$ sem muitos detalhes. Os detalhes e o melhor acabamento podem encarecer muito um objeto, necessitando de mais horas/máquina.

Muitas empresas estão prototipando seus produtos, assim como alguns escultores/modeladores estão migrando do fazer manual para a impressão 3D. Se por um lado ganha-se tempo na execução, em comparação com o processo manual, os protótipos estão se distanciando da expressão da linguagem pessoal e individualidade que cada modelador consegue transmitir. Os resultados obtidos exploram os limites de produção proporcionados pela tecnologia em detrimento do original, porque esses efeitos se aproximam muito uns aos outros perdendo a identidade artística do autor. Os melhores equipamentos que apresentam resultados em diferentes polímeros e outros materiais ainda têm um custo muito elevado.

Existem vários programas 3D utilizados para desenhar no computador as propostas projetuais, e os cursos de Design adquirem aquele que melhor atende as suas necessidades. Os desenhos para serem impressos em 3D, necessitam passar por mais uma etapa na qual o arquivo deve ser fechado para evitar erro na impressão. Os alunos necessitam dominar estes programas, e ter suporte para evitar o erro que, neste caso, ainda está saindo caro, por ser um serviço terceirizado.

Quando o desenho está correto, após a finalização da impressão, é possível fazer um teste da forma do artefato para verificar se está adequado a sua função. Em caso de qualquer correção ou alteração de projeto, além de ajustar o arquivo do desenho, será necessário imprimir a peça novamente, fato que, naturalmente, implica em mais investimento de tempo e dinheiro. Enquanto o estudante não domina os programas de desenho 3D, muitos ajustes são necessários. 
Neste momento de transição, no qual os alunos ainda não dominam os programas como se espera, e as escolas estão começando a adquirir os equipamentos, mas ainda não fizeram os treinamentos adequados de seus funcionários, os jovens ficam ansiosos por utilizar os novos recursos, mas nem todos obtêm uma recompensa gratificante em seus resultados.

Faz-se imprescindível mostrar que as pesquisadoras trazem aqui a necessidade da discussão com relação ao processo educacional pelo qual os cursos de Design estão passando por fazerem a escolha entre um ou outro processo e não pela convergência das tecnologias e do processo manual.

O designer contemporâneo é concebido como um profissional criativo e que, ao estar no processo de formação, precisa vivenciar e sentir sua sensibilidade criativa para desenvolver produtos, às vezes em escala industrial, mas com as percepções técnicas e manuais.

\section{Considerações finais}

As tecnologias computacionais são efêmeras e geram novas demandas de profissionais e de produção; tais mudanças trazem novas possibilidades sendo rapidamente absorvidas pelos usuários.

A impressão 3D, no processo de aprendizagem, é adequada para ser utilizada em situações específicas quando, por exemplo, o desenho do projeto é rigorosamente correto e mais rápido de ser executado sem erros ou modificado pelo usuário. Já nos novos projetos, que são a base no curso de Design, os alunos necessitam de alfabetização digital mais aprofundada, visando o uso de programas específicos para essas necessidades.

Em um vídeo gravado recentemente, o modelador Wesley Iguti, que nasceu e cresceu aprendendo a arte da modelagem manual e hoje desenvolveu habilidade para trabalhar nas duas técnicas, afirma que:

O modelador analisa e observa o desenho do produto a ser modelado e estuda qual ferramenta é mais adequada para a representação da forma; 
sempre levando em consideração o custo / benefício, a qualidade e o tempo de execução. Tem situações que vale mais a pena usar a impressão 3D, em outras é melhor o tradicional - manual. O trabalho executado manualmente apresenta um valor artístico superior na forma representada. Ao representar a forma física, já vai solucionando ele fisicamente. [...] (IGUTI, 2015) $)^{9}$

Vale ressaltar que no meio da alta tecnologia da impressão 3D, ainda hoje as figuras do famoso Museu de cera Madame Tussauds, são feitas à mão cuidadosamente do começo ao fim da modelagem, por escultores; demonstrando o valor que a modelagem manual continua expressando em pleno século XXI.

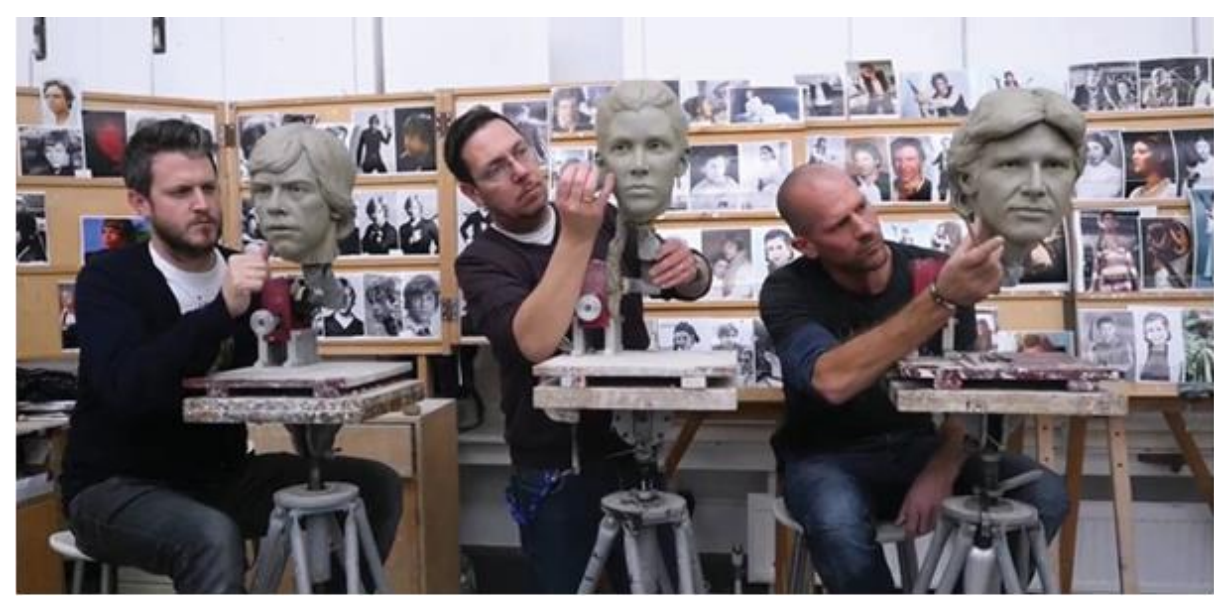

Fonte - https://www.madametussauds.com/London/
Figura $3-$

Modelagem manual dos personagens do filme Star Wars para museu de cera Madame Tussauds.

O perfil dos alunos e as suas necessidades mudaram, é preciso de ajustes nos programas de ensino buscando suprir as novas lacunas desta geração tecnológica.

As Universidades precisam se adequar com as novas ferramentas tecnológicas, proporcionando um espaço ao aluno que permita a experimentação desde o início dos projetos. Fornecer equipamentos e estruturas necessárias para a criação, tanto manuais quanto tecnológica, dando ao aluno a opção de escolha de acordo com a etapa do projeto, sempre orientado pelo professor.

\footnotetext{
${ }^{9}$ Transcrição livre da autora.
} 
Será necessário algum tempo até que todas as Universidades estejam com estes espaços de aprendizado completos e funcionando, pois estas tecnologias ainda têm um custo muito elevado principalmente aqui no Brasil.

A alfabetização manual deve ser iniciada nas disciplinas introdutórias, para instrumentalizar o aluno e servir de base sensório-motora e como conhecimento prático da sua formação, possibilitando entender e trabalhar no universo virtual.

Para os trabalhos de conclusão de curso (TCC) em que são fundamentais os modelos de apresentação com qualidade para expor as bancas de avaliação, deve-se oferecer ao aluno a opção de escolha entre as duas técnicas, verificando o melhor custo / benefício e tempo. A manual, que tem seu custo mais baixo, mas necessita de maior dedicação e tempo para a sua execução com qualidade ou a impressão 3D, que pode apresentar tanto um modelo visual, como funcional, aproveitando que nesta fase os desenhos já estão prontos. Para este recurso, o aluno precisa contratar uma prestadora do serviço fora da faculdade, não necessitando de muito tempo para a sua execução, pois em dois a três dias recebe o modelo de volta finalizado, ou faltando somente uma pintura, mas essa técnica requer um gasto maior de dinheiro, devido ao alto custo ainda cobrado das prestadoras. Fica claro que o processo criativo individual e a subjetividade do designer são tênues quando a aprendizagem tem como protagonista a tecnologia e não o aluno.

São poucos os cursos superiores de Design que possuem impressoras 3D, podendo, assim, oferecer esta tecnologia ao aluno. No entanto, apesar da facilidade de acesso aos jovens, eles adquirem conhecimentos restritos àqueles programas ou técnica de impressão adotada pela Escola.

Na primeira etapa da pesquisa, mostramos o posicionamento das pesquisadoras ao defendermos a opção por uma convergência de processos, manual e tecnológico que pode ser o caminho mais universal e completo para a formação do Designer contemporâneo.

Segundo Theodor Fischer, "Não há qualquer linha divisória nítida entre a ferramenta e a máquina (...) desde que o homem domine a máquina e faça dela uma ferramenta..." (apud PEVSNER, 1995, p.22). 
Trazemos uma discussão antiga a respeito da sobreposição da máquina ao desejo do homem, como Deleuze e Guatarri tratavam no século passado; no entanto, o foco está em desvalorizar o processo manual devido à hipervalorização da tecnologia computacional, não como ferramenta, mas como máquina de fazer conhecimento pronto para os alunos, desvalorizando a capacidade criativa de modelar.

\section{Referências}

CUPANI, Alberto. A tecnologia como problema filosófico: três enfoques. Scientle studia, São Paulo, v. 2, n. 4, p. 493-518, 2004.

FEIX, Giovana. As impressoras 3D podem mudar a sala de aula? São Paulo: Instituto Claro, 2015. Disponível em: <https://www.institutoclaro.org.br/blog/as-impressoras-3d-podemmudar-a-sala-de-aula-/>. Acesso em maio 2015.

FOCILLON, Henri. A vida das formas: seguido de elogio da mão. Lisboa: Edições 70, 2001.

GANDIN, Adriana. Usar tecnologia prepara melhor novos professores. In: Diário de Inovações. São Paulo: Provir, 2014. Disponível em:

<http://porvir.org/diariodeinovacoes/usar-tecnologia-prepara-melhor-novosprofessores/20141112>. Acesso em maio 2015.

GOMES FILHO, João. Design do objeto: bases conceituais. São Paulo: Escritura, 2006.

HARDAGH, Cláudia Coelho; ALLEGRETTI, Sonia Maria Macedo; HESSEL, Ana Maria DiGrado; ERIGLEIDSON, José da Silva. Aprendizagem nas redes sociais virtuais: 0 potencial da conectividade em dois cenários. Revista Cet, São Paulo, v. 01, n. 02, p. 54-60, abr., 2012.

HUNTER, Ian; GRATZNER, Matthew. Documentário Maravilhas Modernas - Modelos. USA: History Channel, 2000.

IGUTI, Wesley, Vídeo polêmica VP. São Paulo, 2015. Acervo do profissional.

IMPRESSÃO 3D na sala de aula também. São Paulo: Portal Impressão 3D, 2014. Disponível em: <http://impressao3dprinter.com.br/blog/2014/04/impressao-3d-na-sala-de-aulatambem/>. Acesso em maio 2015.

MARTINS, Vinicius Silveira. Competências em disciplinas de projeto de Produto. Mestrado em Design pela UniRitter Design, Educação e Inovação. Porto Alegre: 2014.

NADAL, Paula. 5 tendências educacionais segundo o Horizon Report. São Paulo: Instituto Claro, 2015. Disponível em: <https://www.institutoclaro.org.br/blog/as-impressoras-3dpodem-mudar-a-sala-de-aula-/>. Acesso em maio 2015. 
OLIVEIRA, Emilio Augusto Gomes de; LIRA, Naiany Keity Nanes de; MORAIS, José Wilson de. A técnica de sketching à mão livre no processo metodológico do design de produtos. Caruaru: Anais II JORNADA DE ENSINO PESQUISA E EXTENSÃO, 2010. p. 52-57.

OLIVEIRA, Ismael. Impressão 3D: o futuro chegou? In: Canal do ensino [Blog]. São Paulo, 2015. Disponível em: <http://canaldoensino.com.br/blog/impressao-3d-o-futuro-chegou2>. Acesso em maio 2015.

PEVSNER, Nikolaus. Os pioneiros do desenho moderno. São Paulo: Martins Fontes, 1995. POSTMAN, Neil. Tecnopólio: a rendição da cultura à tecnologia. São Paulo: Nobel, 1994.

SANTAELLA, Lúcia. A aprendizagem ubíqua substitui a educação formal? Revista ReCeT de Computação e Tecnologia da PUC-SP. São Paulo: Departamento de Computação/FCET/PUC-SP, v. 2, n. 1, p. 17-22, out., 2010.

SILVA, José Renato de Castro e; FERREIRA, Bráulio Vinícius. Maquete: a modelagem manual no ensino de Arquitetura e Urbanismo.

<http://www2.unucseh.ueg.br/ceped/edipe/anais/vedipefinal/pdf/gtog/co\%20grafica/Josr\% 20Renato\%20de\%20Castro\%20e\%20Silva.pdf >. Acesso em ago., 2015.

VIGOTSKI, Lev Semenovitch. A formação social da mente. São Paulo: Martins Fontes, 1991.

\section{Outras Fontes Consultadas}

BHBIT. Como as impressoras 3D podem transformar a educação. Tecnologia e Terceiro Setor. Disponível em: https://www.bhbit.com.br/como-impressoras-3d-podemtransformar-educacao/. Acesso em maio de 2015.

BIBANO, Bianca. Salas de aula invertidas, uso de impressora 3D e outras tendências do ensino superior. São Paulo 09/03/2014. Veja Abril. Disponível em:

http://veja.abril.com.br/noticia/educacao/salas-de-aula-invertidas-uso-de-impressora-3d-eoutras-tendencias-do-ensino-superior/. Acesso em maio 2015.

Universidade do Estado de Santa Catarina - UDESC

Programa de Pós-Graduação em Educação - PPGE

Revista Linhas

Volume 17 - Número 35 - Ano 2016

revistalinhas@gmail.com 